\title{
Effects of Additional Rifle-Carriage Training on Physiological Markers and Roller-Skiing Performance in Well-Trained Biathletes
}

\author{
Malin Jonsson Kårström ${ }^{1} \cdot$ Kerry McGawley $^{1} \cdot$ Marko S. Laaksonen $^{1}$
}

Received: 7 September 2020 / Accepted: 7 January 2021 / Published online: 25 May 2021

(c) The Author(s) 2021

\begin{abstract}
Purpose The purpose was to investigate whether an increased amount of training while carrying the rifle affects skiing in well-trained biathletes at submaximal and maximal workloads during a pre-season period lasting a minimum of 12 weeks. Methods Seventeen well-trained biathletes ( 9 females, 8 males) were assigned to an intervention (IG, $n=10)$ or control (CG, $n=7$ ) group. Before (T1) and after (T2) the training intervention all participants performed, using treadmill roller-skiing, a submaximal test without the rifle on one day and two submaximal workloads and a maximal time trial (TT) with the rifle on a subsequent day. Between T1 and T2 all participants performed a minimum of 12 weeks of normal training, the only difference between groups being that IG performed more of their training sessions carrying the rifle.

Results IG performed more training compared to CG $(15.4 \pm 1.1 \mathrm{vs.} 11.2 \pm 2.6 \mathrm{~h} /$ week, $P<0.05)$, including a higher amount of training with the rifle ( $3.1 \pm 0.6$ vs. $1.1 \pm 0.3 \mathrm{~h} /$ week, $P<0.001)$. Speed at $4 \mathrm{mmol} / \mathrm{L}$ of blood lactate increased significantly for CG from T1 to T2 $(P=0.028)$, while only tended to increase for IG $(P=0.058)$. Performance during the TT, $\mathrm{VO}_{2 \max }$ and the aerobic metabolic rate increased significantly from $\mathrm{T} 1$ to $\mathrm{T} 2$, although the differences disappeared when including the speed at baseline as a covariate.

Conclusion According to the present results, increasing training while carrying the rifle by $2 \mathrm{~h} /$ week does not appear to improve skiing performance in well-trained biathletes. In addition, physiological markers at submaximal and maximal intensities while carrying the rifle were not affected after the training intervention.
\end{abstract}

Keywords Anaerobic energy contribution · Gross efficiency $\cdot$ Lactate threshold $\cdot$ Nordic skiing $\cdot$ Oxygen uptake $\cdot$ Training intervention

\section{Introduction}

Biathlon is a winter sport combining rifle shooting with cross-country (XC) skiing. The duration of a biathlon competition is $20-50$ min and includes $6-20 \mathrm{~km}$ of XC skiing while carrying the rifle (minimum weight $3.5 \mathrm{~kg}$ ), divided by two or four shooting sessions in prone and standing positions. The competition time in biathlon is a result of the skiing speed and shooting speed and accuracy, with skiing speed explaining $~ 50 \%-65 \%$ of the variance in overall performance, depending on the competition discipline $[5,18$, 19].

Malin Jonsson Kårström

malin.m.jonsson@miun.se

1 Department of Health Science, Swedish Winter Sports Research Centre, Mid Sweden University, Östersund, Sweden
In accordance with other endurance-based sports [10], maximal oxygen uptake $\left(\mathrm{VO}_{2 \max }\right)$, speed at the lactate threshold or at $4 \mathrm{mmol} / \mathrm{L}\left(\operatorname{speed}_{@ 4 ~ m m o l}\right)$ of blood lactate concentration (BLa), efficiency of movement and anaerobic energy contribution have all been shown to be important for biathlon skiing performance and/or national ranking points $[9,13,14,23,24]$. When skiing with the rifle, oxygen uptake $\mathrm{VO} 2$ ), ventilation rate $\mathrm{VE}$ ), heart rate (HR), BLa and gross efficiency (GE) are all increased compared to skiing without the rifle $[9,25,26]$, while speed ${ }_{@ 4 ~ m m o l}$, anaerobic energy contribution and roller-skiing performance during a $3-4 \mathrm{~min}$ TT are decreased [9].

Elite biathletes perform 700-900 h/year of physical training consisting of $\sim 80 \%$ of low-intensity $(60 \%-80 \%$ of maximal heart rate, $\mathrm{HR}_{\max }$ ), $4 \%-5 \%$ of moderate-intensity $\left(80 \%-90 \%\right.$ of $\left.\mathrm{HR}_{\max }\right)$ and $5 \%-6 \%$ of high-intensity ( $>90 \%$ of $\mathrm{HR}_{\max }$ ) training, while the final $10 \%$ is dedicated to improving strength and speed [15]. The low-intensity 
training is performed as (roller-) skiing using the classical and skating techniques, cycling and running, while the largest part of the high-intensity training is performed as skate (roller-) skiing [15]. In addition, $15 \%-30 \%$ of the endurance training is performed while carrying the rifle $[9,15]$.

Previous research from military populations has shown that load-carrying performance was enhanced to a greater extent when at least one training session per week included military load-carriage exercises [7, 29, 30], although no studies have investigated how load-carrying training affects well-trained biathletes.

Rifle carriage affects physiological variables (e.g. $\mathrm{VO}_{2}$, HR, BLa, GE, speed $@ 4$ mmol and anaerobic energy contribution) and roller-skiing performance, but it is still unknown how well-trained biathletes are affected by an increased amount of rifle-carriage training. This can be valuable knowledge for biathlon coaches and biathletes when planning, performing and evaluating training. Therefore, the purpose of this study was to investigate whether an increased amount of training while carrying the rifle affects the physiology and performance of biathlon skiing in well-trained biathletes at submaximal and maximal workloads during a pre-season training period lasting a minimum of 12 weeks.

\section{Materials and Methods}

\section{Participants}

Seventeen well-trained Swedish biathletes (nine females and eight males) competing at national and international levels volunteered to participate in the study and were assigned to one of two training groups: an intervention group (IG; five females and five males) or a control group (CG; four females and three males). The IG consisted of members of the Swedish national development team, while the CG consisted of athletes from the Swedish national junior team and the ski university team. The age, body height and mass of the IG and CG participants were $22.5 \pm 1.5$ vs. $21.5 \pm 3.5$ years, $175 \pm 7$ vs. $173 \pm 8 \mathrm{~cm}$ and $71.1 \pm 6.5$ vs. $68.5 \pm 4.8 \mathrm{~kg}$, respectively (all $P>0.05$ ). All participants were informed verbally and in writing about the nature of the study before providing their written consent to participate. The study was preapproved by the Swedish Ethical Review Authority in Uppsala (2019-04527) and was performed in accordance with the Declaration of Helsinki.

\section{Study Overview}

At the beginning of the training season, during a 3-week period in May-June, all participants visited the laboratory twice to complete two separate testing sessions (T1). Both of the T1 testing sessions were performed as treadmill roller-skiing using the gear 3 skating sub-technique. A submaximal test (including 3-6 workloads) without the rifle was performed during the first session and the second session consisted of two fixed submaximal workloads and a maximal TT while carrying the rifle (Fig. 1). All participants used the same rifle during testing (weighing $3.5 \mathrm{~kg}$ ) and their own biathlon harness (weighing $0.2 \mathrm{~kg}$ ). After the intervention period, the same two testing sessions were performed using the same methods during a 5-week period in September-October (T2). Between T1 and T2, all athletes performed a minimum of 12 weeks of training according to their normal training programs, with IG performing more of their normal training sessions while carrying the rifle.

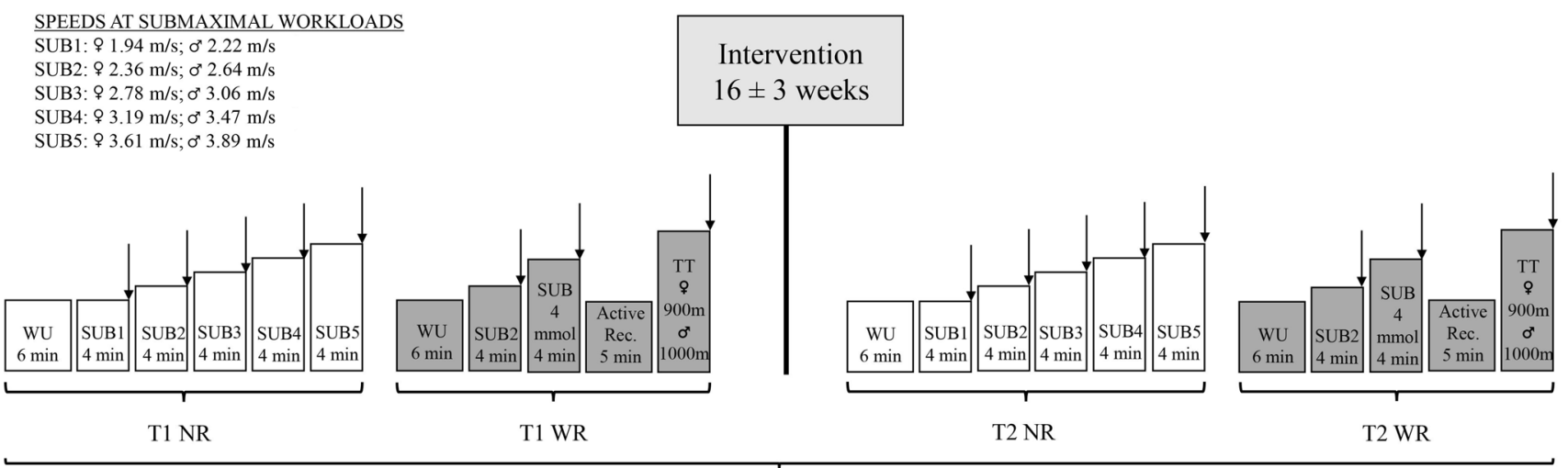

GRADIENT: $93.5^{\circ} ; 0^{\circ} 4.5^{\circ}$

ALL TESTS IN GEAR 3

Fig. 1 Schedule of the testing procedure before (T1) and after (T2) the training intervention for skiing without (NR) and with (WR) the rifle. The arrows show measurements of blood lactate and ratings of perceived exertion, in addition to respiratory responses and heart rate that were measured throughout the submaximal workloads and maximal time trial (TT). $q$ females, $\lesssim$ males, $W U$ warm up, active rec. active recovery 


\section{Testing Procedures}

All tests were carried out using treadmill roller-skiing (belt dimensions $3.3 \times 2.5 \mathrm{~m}$; Rodby Innovation AB, Vänge, Sweden). The participants wore a safety harness around their waist connected to an emergency brake fixed to the ceiling, stopping the treadmill within $1 \mathrm{~s}$ in the case of a fall. All participants used Pro-Ski S2 roller-skis (Sterners, Dala-Järna, Sweden) equipped with NNN bindings (Rottefella, Klockarstua, Norway), which were pre-warmed for at least $60 \mathrm{~min}$ in a heating box before each test to minimize the variation in rolling resistance $\left(\mu_{\mathrm{R}}\right)$. The $\mu_{\mathrm{R}}$ coefficient (mean 0.0224) was determined as described previously by Ainegren et al. [1]. During all submaximal and maximal tests expired air was sampled using an AMIS 2001 metabolic system (model C, Innovision A/S, Odense, Denmark) with a 10-s sampling interval. The equipment was calibrated before each testing session using a calibration gas of a known mixture (16.0\% $\mathrm{O}_{2}$ and $4.5 \% \mathrm{CO}_{2}$, Air Liquide, Kungsängen, Sweden) and a 3-L syringe (Hans Rudolph, Kansas City, Missouri, USA) at low, medium and high flow rates. Heart rate was measured throughout the tests at 5-s intervals using a heart rate monitor (Polar S810, Polar Electro Oy, Kempele, Finland).

For the test without the rifle, the participants rested in a supine position upon arrival before a capillary blood sample was taken from the fingertip for measuring resting BLa (Biosen S_Line, EKF diagnostics, Magdeburg, Germany). Body height and mass were subsequently measured (Seca 764, Hamburg, Germany). The female and male participants then performed a standardized warm-up for $6 \mathrm{~min}$ at $1.94 \mathrm{~m} / \mathrm{s}$ $(7 \mathrm{~km} / \mathrm{h})$ and $2.22 \mathrm{~m} / \mathrm{s}(8 \mathrm{~km} / \mathrm{h})$, respectively. The first 4-min stage of the submaximal test was prescribed at the warmup intensity, after which the speed increased by $0.42 \mathrm{~m} / \mathrm{s}$ $(1.5 \mathrm{~km} / \mathrm{h})$ every $4 \mathrm{~min}$. The gradient was constant $\left(3.5^{\circ}\right.$ for the females, $4.5^{\circ}$ for the males) and between each workload the treadmill stopped for $60 \mathrm{~s}$ for fingertip blood sampling and the recording of the rating of perceived exertion (RPE; Borg scale 6-20) for breathing, arms and legs. The submaximal test consisted of 3-6 workloads, depending on the participant's physical capacity, and was terminated when the respiratory exchange ratio (RER) was $>1.00, \mathrm{~V}_{\mathrm{E}}(\mathrm{L} / \mathrm{min}) /$ $\mathrm{VO}_{2}\left(\mathrm{~L} / \mathrm{min}\right.$ ) was $>30$ and $\mathrm{HR}$ was $>90 \%$ of reported $\mathrm{HR}_{\text {max }}$.

The subsequent test with the rifle was performed using similar gradients, speeds, durations and measurements as for the test without the rifle, but the participants only completed two of the submaximal workloads: the second workload (females $2.36 \mathrm{~m} / \mathrm{s}[8.5 \mathrm{~km} / \mathrm{h}]$ and males $2.64 \mathrm{~m} / \mathrm{s}$ [9.5 km/h]), followed by the workload closest to, but not above, $4 \mathrm{mmol} / \mathrm{L}$ of BLa (Sub4mmol; IG $3.13 \pm 0.21 \mathrm{~m} / \mathrm{s}$ and CG $3.02 \pm 0.17 \mathrm{~m} / \mathrm{s} P=0.417)$. The participants then recovered passively for 2 min before completing a 5-min re-warm-up (including $3 \mathrm{~min}$ of active recovery and two 15 -s self-paced sprints separated by 45 -s of active recovery) followed by the maximal TT. The participants were able to adjust the speed of the treadmill according to their position on the belt via a laser system [27]. Moving to the front or back of the belt increased or decreased the speed by 0.19 or $0.11 \mathrm{~m} / \mathrm{s}^{2}$, respectively, while skiing in the middle of the belt kept the speed constant. The simulated TT consisted of $900 \mathrm{~m}$ of roller-skiing at a gradient of $3.5^{\circ}$ for the females, and $1000 \mathrm{~m}$ at a gradient of $4.5^{\circ}$ for the males, to be completed as fast as possible. During the TT, expired air and HR were measured throughout and a fingertip blood sample was collected 2 min after the test for the analysis of maximal BLa. The two testing sessions were repeated after the intervention period (T2).

\section{Training Intervention}

During the training intervention participants performed their normal training, the only difference being that IG aimed to carry their rifle during at least two training sessions per week. The CG skied with the rifle occasionally, according to their normal training plan for the time of year. All participants registered their training time, intensity and activity in the Swedish Biathlon Federation's official online training diary (Maxpulse, Johan Bergman, Östersund, Sweden) and a training session was manually marked by the participants when training with the rifle. All athletes reported their training intensity according to five training zones (defined by percentages of $H R_{\max }$ ), which are general training zones used by the Swedish Biathlon teams: A1 (60\%-75\%, low), A2 (76\%-80\%, moderate), A3- (81\%-85\%, moderate), A3 (86\%-95\%, high) and A3+ (>95\%, high). Strength training was reported as the number of sessions and type (maximal, endurance or stability).

\section{Calculations}

Respiratory values $\left(\mathrm{VO}_{2}, \mathrm{VCO}_{2}, \mathrm{~V}_{\mathrm{E}}\right.$ and RER $)$ and $\mathrm{HR}$ were calculated as the mean of the last $30 \mathrm{~s}$ of each workload during the submaximal workloads and the highest consecutive 30 -s values during the TT as maximal values. The speed $_{@ 4 \text { mmol }}$ was calculated from the individual exponential relationships between BLa and speed. Power output (PO) was calculated as the power exerted to elevate the total mass against gravity and to overcome the $\mu_{\mathrm{R}}$ during roller-skiing according to the equation by Andersson et al. [2].

The aerobic metabolic rate $\left(\mathrm{MR}_{\mathrm{ae}}\right)$ was determined from the mean $\mathrm{VO}_{2}$ and RER during the last $30 \mathrm{~s}$ of the highest submaximal workload with a RER $<1.00$ for skiing with and without the rifle and was subsequently used to calculate GE [2]. 
For the $\mathrm{TT}$, the total metabolic demand (MR $\mathrm{DEMAND})$ was calculated using the GE method [2], and anaerobic metabolic rate $\left(\mathrm{MR}_{\mathrm{an}}\right)$ was then calculated as:

$\mathrm{MR}_{\mathrm{an}}(W)=\mathrm{MR}_{\text {DEMAND }}-\mathrm{MR}_{\mathrm{ae}}$,

where $\mathrm{MR}_{\mathrm{ae}}$ was calculated as described above using the mean $\mathrm{VO}_{2}$ for the entire TT, assuming $\mathrm{RER}=1.0 . \mathrm{MR}_{\mathrm{an}}$ was integrated overtime for the TT and converted to an accumulated $\mathrm{O}_{2}$ deficit $\left(\Sigma \mathrm{O}_{2 \text { deficit }}\right)$ by multiplying with a constant for the $\mathrm{mL} \mathrm{O}_{2}$ equivalent per joule of 0.047801 and assuming $100 \%$ carbohydrate utilization [28].

\section{Statistical Analyses}

All statistical analyses were processed using SPSS 24.0 Software (SPSS, Inc., Chicago, IL) and the level of statistical significance was set at $\alpha \leq 0.05$. Data are presented as mean \pm standard deviation (SD), except for RPE where data are presented as the median and interquartile range (IQR). All variables were tested for normal distribution using the Shapiro-Wilks test of normality, which showed a normal distribution for the majority of the variables. Baseline values (T1) for submaximal and maximal roller-skiing were compared between groups using Mann-Whitney $U$ tests. To investigate whether there were any differences between the two groups in training, Mann-Whitney $U$ tests were also used to compare the training period durations, number of sick days, total training volume, training intensities, training with the rifle and number of strength-training sessions.

For the submaximal tests (with and without the rifle) and the maximal TT, a mixed between-within subjects 2-way ANOVA (2 groups, 2 test occasions) was used to investigate differences in respiratory variables, BLa, HR, speed $@ 4$ mmol, performance, GE, RPE, $\mathrm{MR}_{\mathrm{ae}}$ and $\mathrm{MR}_{\mathrm{an}}$. If the variable was not-normally distributed or if a significant difference was observed in the ANOVA test, a Mann-Whitney $U$ test or Wilcoxon Signed Rank test was used, depending on whether the difference was found between groups or test occasions, to identify specific differences. Data for the maximal TT was also tested using a 2-way ANCOVA, using baseline speed during the TT as a covariate.

The change score (difference between T1 and T2) was calculated and compared between groups using Mann-Whitney $U$ tests. Effect sizes were calculated using Cohen's $D$ (for training loads) or partial Eta square $\left(\eta_{\mathrm{p}}{ }^{2}\right.$, for submaximal and maximal values), with the criteria 0.2 or $0.02=$ small effect, 0.5 or $0.13=$ moderate effect and 0.8 or $0.26=$ large effect, respectively [3].

\section{Results}

\section{Intervention Period}

The training intervention lasted $16.2 \pm 3.4$ weeks for IG and $15.8 \pm 3.2$ weeks for CG $(P>0.999)$, with IG performing a higher amount of training during the intervention period $(15.4 \pm 1.4$ vs. $11.2 \pm 2.6 \mathrm{~h} /$ week; $P=0.001)$ and reporting fewer sick days $(3.7 \pm 3.0$ vs. $11.4 \pm 6.3$ days; $P=0.002$ ) compared to CG. The training was mostly performed as skate roller-skiing (IG $39.0 \% \pm 3.0 \%$ vs. CG $37.8 \% \pm 5.8 \% ; P=0.536)$ and running (IG $30.9 \% \pm 7.6 \%$ vs. CG $36.6 \% \pm 7.0 \% ; P=0.133)$, with the remaining training performed as classical roller-skiing, cycling or other (Table 1). Most of the training was performed at a low intensity $(82.4 \% \pm 3.2 \%$ vs. $86.4 \% \pm 2.1 \% ; P=0.014)$, followed by moderate $(10.7 \% \pm 2.5 \%$ vs. $6.7 \% \pm 2.6 \%$; $P=0.019)$ and high $(6.9 \% \pm 1.2 \%$ vs. $7.0 \% \pm 1.5 \%$; $P=0.887$ ) intensities for IG and CG, respectively. The IG trained with the rifle more frequently and for a longer time compared to CG $(1.5 \pm 0.6$ vs. $0.6 \pm 0.2$ sessions/

Table 1 Mean \pm SD training durations (in h) for the various activity modes and intensities (low, moderate and high) during the $\sim 16$-week training period for the intervention (IG; $n=10)$ and control (CG; $n=7)$ groups

\begin{tabular}{|c|c|c|c|c|c|c|c|c|c|}
\hline & \multicolumn{9}{|c|}{ Training intensity } \\
\hline & \multicolumn{2}{|l|}{ Low } & \multicolumn{2}{|l|}{ Moderate } & \multicolumn{2}{|l|}{ High } & \multicolumn{3}{|l|}{ Total } \\
\hline & IG & $\mathrm{CG}$ & IG & CG & IG & CG & IG & CG & ES \\
\hline Total training & $206.2 \pm 50.1$ & $154.7 \pm 55.9$ & $27.8 \pm 11.9$ & $12.1 \pm 5.7 * *$ & $17.8 \pm 6.4$ & $12.1 \pm 3.8^{*}$ & $251.8 \pm 66.4$ & $179.0 \pm 62.9^{*}$ & 0.49 \\
\hline RS skating & $68.8 \pm 17.1$ & $53.3 \pm 20.0$ & $17.9 \pm 7.2$ & $7.3 \pm 3.5 * *$ & $11.3 \pm 4.1$ & $6.5 \pm 2.5^{*}$ & $98.0 \pm 27.0$ & $67.1 \pm 24.0^{*}$ & 0.52 \\
\hline RS skating WR & $29.6 \pm 11.0$ & $11.2 \pm 3.5 * * *$ & $12.9 \pm 4.8$ & $1.6 \pm 1.4 * * *$ & $8.8 \pm 3.9$ & $4.0 \pm 1.3 * *$ & $51.3 \pm 18.7$ & $16.8 \pm 5.3^{* * *}$ & 0.78 \\
\hline RS classic & $48.5 \pm 17.8$ & $34.0 \pm 19.1$ & $3.5 \pm 2.1$ & $1.4 \pm 1.7$ & $0.2 \pm 0.3$ & $0.2 \pm 0.4$ & $52.2 \pm 18.5$ & $35.6 \pm 20.8$ & 0.39 \\
\hline Running & $68.2 \pm 25.7$ & $58.6 \pm 24.7$ & $5.8 \pm 3.5$ & $2.7 \pm 2.3$ & $5.5 \pm 2.8$ & $5.9 \pm 2.0$ & $79.5 \pm 30.7$ & $66.3 \pm 26.9$ & 0.22 \\
\hline Cycling & $19.9 \pm 15.6$ & $4.8 \pm 2.1 *$ & $0.1 \pm 0.2$ & - & $0.2 \pm 0.3$ & $0.2 \pm 0.5$ & $20.2 \pm 15.9$ & $5.0 \pm 2.2 *$ & 0.56 \\
\hline Other & $3.7 \pm 4.1$ & $4.0 \pm 3.1$ & $0.5 \pm 0.6$ & $0.8 \pm 0.9$ & $0.5 \pm 0.9$ & $0.2 \pm 0.4$ & $4.8 \pm 4.1$ & $5.0 \pm 3.7$ & -0.03 \\
\hline
\end{tabular}

Different from IG $* P<0.05, * * P<0.01, * * * P<0.001$

$R S$ roller-skiing, $W R$ with the rifle, $E S$ effect size 
week and $3.1 \pm 0.6$ vs. $1.1 \pm 0.3 \mathrm{~h} /$ week; both $P<0.001$ ). All training with the rifle was performed as roller-skiing using the skating technique and represented $19.9 \% \pm 2.9 \%$ and $9.8 \% \pm 2.4 \%$ of the total skate roller-skiing time for IG and CG, respectively $(P<0.001)$. The IG performed $1.9 \pm 0.5$ sessions/week of strength training $(55 \%$ maximal, $20 \%$ endurance and $25 \%$ stability) in comparison to $1.2 \pm 0.6$ sessions/week for CG (55\% maximal, $30 \%$ endurance and $15 \%$ stability; $P=0.025$ ).

\section{Submaximal Responses Without the Rifle}

During T1, IG performed 5-6 workloads while CG performed 3-5 workloads, due to the athletes' individual capacities. During T2, two athletes were able to ski one additional workload compared to T1 (both from CG), while two athletes in IG did not perform the submaximal test without the rifle due to sickness and/or training camps. At submaximal levels 2, 3, and 5 the BLa was lower during $\mathrm{T} 2$ compared to $\mathrm{T} 1$ and when analyzing

Table 2 Mean \pm SD responses to skiing without the rifle during five submaximal workloads for testing before (T1) and after (T2) the training intervention. The number of submaximal workloads is dictated by the individual capacity of the participants

\begin{tabular}{|c|c|c|c|c|c|c|c|}
\hline & \multicolumn{2}{|c|}{ Intervention group } & \multicolumn{2}{|c|}{ Control group } & \multicolumn{3}{|c|}{ Significant $p$ value $\left(\eta_{\mathrm{p}}^{2}\right)$} \\
\hline & $\mathrm{T} 1$ & $\mathrm{~T} 2$ & $\mathrm{~T} 1$ & $\mathrm{~T} 2$ & Group & Time & Interaction \\
\hline Submaximal workload 1 & $n=10$ & $n=8$ & $n=7$ & $n=7$ & & & \\
\hline $\mathrm{VO}_{2}(\mathrm{~L} / \mathrm{min})$ & $2.5 \pm 0.5$ & $2.5 \pm 0.5$ & $2.4 \pm 0.5$ & $2.4 \pm 0.5$ & NS (0.007) & NS (0.159) & NS (0.010) \\
\hline $\mathrm{VO}_{2}(\mathrm{~mL} / \mathrm{kg} / \mathrm{min})$ & $34.9 \pm 5.0$ & $34.5 \pm 5.2$ & $35.3 \pm 5.9$ & $34.9 \pm 5.5$ & NS (0.000) & NS (0.168) & NS (0.010) \\
\hline HR (beats/min) & $139 \pm 13$ & $140 \pm 12$ & $154 \pm 15$ & $152 \pm 9$ & NS $(0.240)$ & NS (0.030) & NS (0.006) \\
\hline RER & $0.88 \pm 0.03$ & $0.91 \pm 0.04$ & $0.90 \pm 0.05$ & $0.91 \pm 0.02$ & NS (0.078) & NS (0.119) & NS (0.074) \\
\hline Blood lactate (mmol/L) & $1.5 \pm 0.4$ & $1.4 \pm 0.3$ & $1.5 \pm 0.8$ & $1.3 \pm 0.4$ & NS (0.007) & NS (0.086) & NS (0.020) \\
\hline Submaximal workload 2 & $n=10$ & $n=8$ & $n=7$ & $n=7$ & & & \\
\hline $\mathrm{VO}_{2}(\mathrm{~L} / \mathrm{min})$ & $2.9 \pm 0.6$ & $2.8 \pm 0.6$ & $2.8 \pm 0.6$ & $2.7 \pm 0.6$ & NS (0.010) & NS (0.125) & NS (0.033) \\
\hline $\mathrm{VO}_{2}(\mathrm{~mL} / \mathrm{kg} / \mathrm{min})$ & $40.1 \pm 5.2$ & $39.5 \pm 5.6$ & $40.1 \pm 5.9$ & $39.9 \pm 5.8$ & NS $(0.000)$ & NS (0.187) & NS (0.072) \\
\hline HR (beats/min) & $153 \pm 14$ & $153 \pm 15$ & $168 \pm 12$ & $163 \pm 9$ & NS (0.205) & NS (0.139) & NS (0.067) \\
\hline RER & $0.90 \pm 0.02$ & $0.92 \pm 0.03$ & $0.92 \pm 0.04$ & $0.93 \pm 0.03$ & NS (0.168) & NS (0.089) & NS $(0.041)$ \\
\hline Blood lactate $(\mathrm{mmol} / \mathrm{L})$ & $1.7 \pm 0.4$ & $1.5 \pm 0.4 *$ & $2.1 \pm 1.0$ & $1.5 \pm 0.5$ & NS (0.027) & $0.010(0.414)$ & NS (0.098) \\
\hline Submaximal workload 3 & $n=10$ & $n=8$ & $n=7$ & $n=7$ & & & \\
\hline $\mathrm{VO}_{2}(\mathrm{~L} / \mathrm{min})$ & $3.3 \pm 0.7$ & $3.2 \pm 0.7$ & $3.1 \pm 0.6$ & $3.1 \pm 0.6$ & NS (0.010) & NS (0.172) & NS (0.067) \\
\hline $\mathrm{VO}_{2}(\mathrm{~mL} / \mathrm{kg} / \mathrm{min})$ & $45.8 \pm 5.8$ & $44.8 \pm 6.6$ & $45.6 \pm 6.5$ & $45.4 \pm 6.3$ & NS (0.000) & $0.046(0.273)$ & NS (0.142) \\
\hline HR (beats/min) & $165 \pm 13$ & $166 \pm 13$ & $179 \pm 9$ & $175 \pm 9$ & NS (0.208) & NS (0.142) & NS (0.172) \\
\hline RER & $0.93 \pm 0.03$ & $0.94 \pm 0.04$ & $0.96 \pm 0.05$ & $0.96 \pm 0.04$ & NS (0.252) & NS (0.012) & NS (0.035) \\
\hline Blood lactate (mmol/L) & $2.6 \pm 0.6$ & $2.1 \pm 0.6^{*}$ & $3.3 \pm 1.5$ & $2.4 \pm 0.7$ & NS (0.105) & $0.004(0.478)$ & NS (0.114) \\
\hline Submaximal workload 4 & $n=10$ & $n=8$ & $n=6$ & $n=7$ & & & \\
\hline $\mathrm{VO}_{2}(\mathrm{~L} / \mathrm{min})$ & $3.6 \pm 0.7$ & $3.6 \pm 0.8$ & $33 \pm 0.6$ & $3.5 \pm 0.7$ & NS (0.073) & NS (0.034) & NS (0.015) \\
\hline $\mathrm{VO}_{2}(\mathrm{~mL} / \mathrm{kg} / \mathrm{min})$ & $50.6 \pm 6.3$ & $50.7 \pm 7.1$ & $48.4 \pm 6.4$ & $50.3 \pm 7.0$ & NS (0.038) & NS (0.004) & NS (0.060) \\
\hline HR (beats/min) & $176 \pm 13$ & $177 \pm 13$ & $186 \pm 6$ & $184 \pm 8$ & NS (0.147) & NS (0.080) & NS (0.043) \\
\hline RER & $0.97 \pm 0.04$ & $0.99 \pm 0.03$ & $1.02 \pm 0.07$ & $1.01 \pm 0.04$ & NS (0.210) & NS 0.001) & NS (0.105) \\
\hline Blood lactate $(\mathrm{mmol} / \mathrm{L})$ & $4.3 \pm 1.1$ & $3.3 \pm 0.8$ & $5.6 \pm 2.7$ & $5.4 \pm 4.0$ & NS (0.134) & NS (0.152) & NS (0.042) \\
\hline Submaximal workload 5 & $n=10$ & $n=8$ & $n=5$ & $n=5$ & & & \\
\hline $\mathrm{VO}_{2}(\mathrm{~L} / \mathrm{min})$ & $3.9 \pm 0.8$ & $4.0 \pm 0.9$ & $3.7 \pm 0.6$ & $3.6 \pm 0.6$ & NS (0.052) & NS (0.000) & NS (0.029) \\
\hline $\mathrm{VO}_{2}(\mathrm{~mL} / \mathrm{kg} / \mathrm{min})$ & $54.8 \pm 6.6$ & $56.0 \pm 7.7$ & $54.3 \pm 5.3$ & $54.8 \pm 5.7$ & NS (0.010) & NS (0.057) & NS (0.000) \\
\hline HR (beats/min) & $185 \pm 12$ & $185 \pm 13$ & $194 \pm 6$ & $190 \pm 7$ & NS $(0.101)$ & NS (0.224) & NS (0.100) \\
\hline RER & $1.04 \pm 0.05$ & $1.05 \pm 0.04$ & $1.07 \pm 0.03$ & $1.05 \pm 0.04$ & NS $(0.101)$ & NS (0.000) & NS (0.220) \\
\hline Blood lactate $(\mathrm{mmol} / \mathrm{L})$ & $7.3 \pm 2.0$ & $5.5 \pm 1.3 *$ & $8.3 \pm 1.2$ & $6.1 \pm 1.2$ & NS (0.124) & $0.001(0.668)$ & NS (0.094) \\
\hline
\end{tabular}

$H R$ heart rate, $N S$ not significant, $R E R$ respiratory exchange ratio, $V O_{2}$ oxygen uptake

*Significantly different from T1 (for the same group) based on Wilcoxon Signed Rank testing, $P<0.05$ 
A

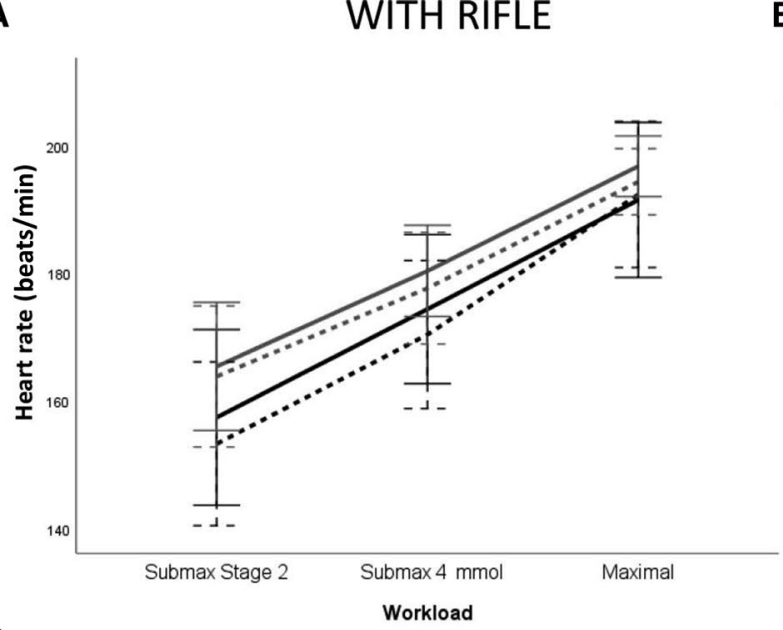

C

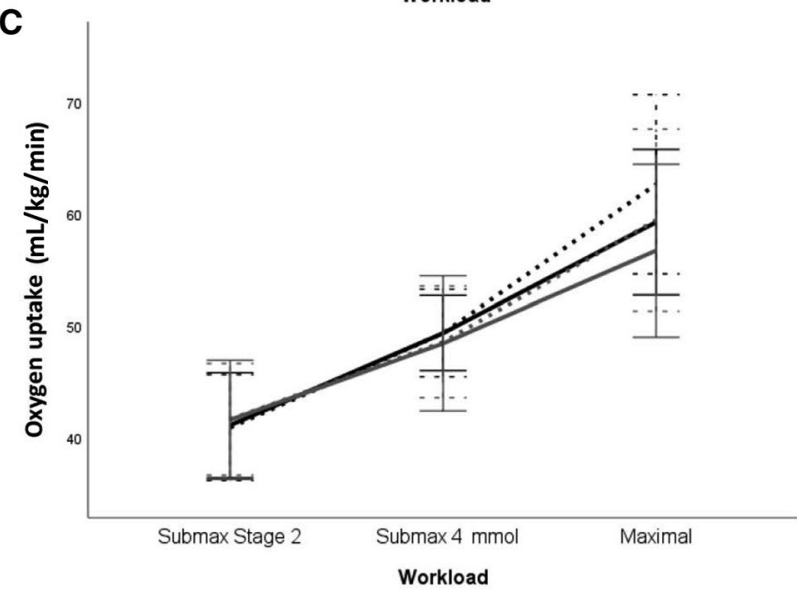

E

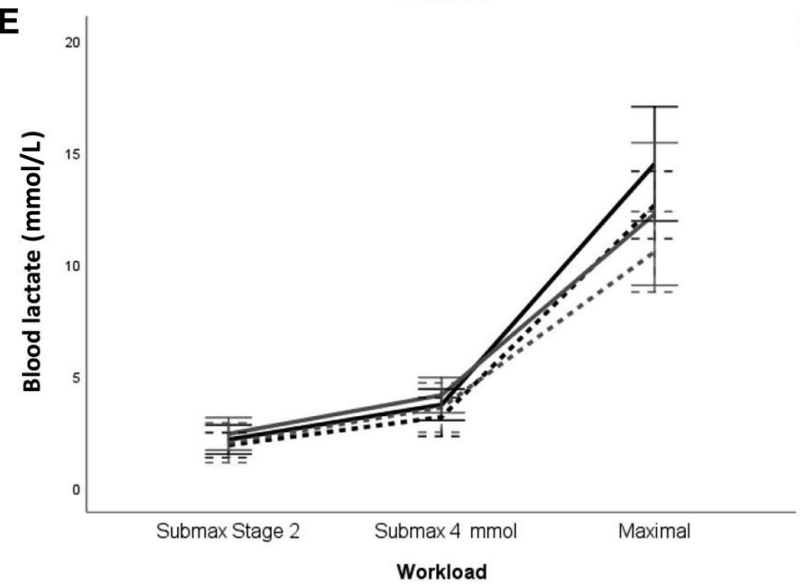

Fig. 2 Mean \pm SD responses to submaximal and maximal roller-skiing for heart rate (a with rifle, $\mathbf{b}$ without rifle), $\mathrm{VO}_{2}$ (c with rifle, $\mathbf{d}$ without rifle) and blood lactate (e with rifle, $\mathbf{f}$ without rifle) for testing

the groups separately these differences were only significant for IG $(P<0.05$; Table 2, Fig. 2). By contrast,

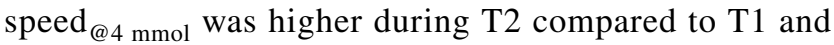
when analyzing the groups separately this difference was significant for CG $(3.00 \pm 0.28$ vs. $3.31 \pm 0.28 \mathrm{~m} / \mathrm{s}$, $P=0.028, \mathrm{ES}=1.107)$, while IG only showed a tendency for an increase $(3.25 \pm 0.19$ vs. $3.47 \pm 0.14 \mathrm{~m} / \mathrm{s}, P=0.058$,

B

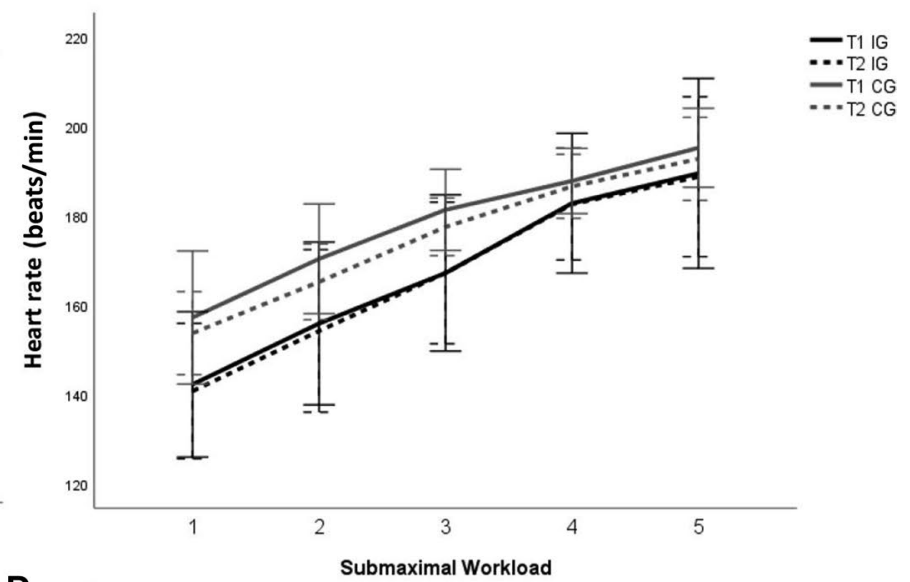

D
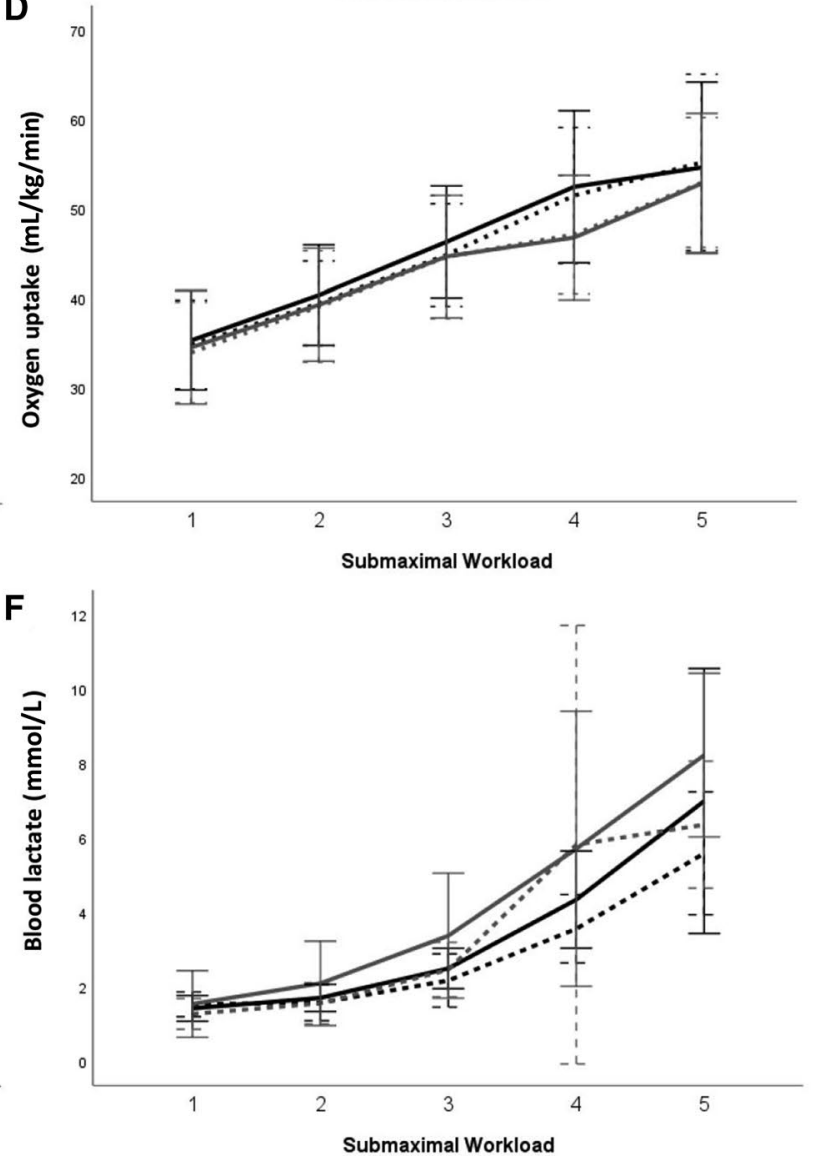

before (T1) and after (T2) the training intervention for the intervention (IG) and control (CG) groups

$\mathrm{ES}=1.318) . \mathrm{GE}$ was not different between $\mathrm{T} 1$ and $\mathrm{T} 2$ $(16.8 \% \pm 0.7 \%$ vs. $16.9 \% \pm 0.9 \%, P=0.534)$ or between IG and CG $(17.2 \% \pm 0.6 \%$ vs. $16.6 \% \pm 0.9 \%, P=0.113)$. No difference in change scores (i.e., differences between $\mathrm{T} 1$ and T2) were found between IG and CG for any of the variables. 


\section{Submaximal Responses with the Rifle}

There were no differences between the two groups or between $\mathrm{T} 1$ and $\mathrm{T} 2$ for respiratory variables, HR, BLa (Table 3, Fig. 2) or RPE for either of the two submaximal workloads or in change scores between $\mathrm{T} 1$ and $\mathrm{T} 2$ for the two groups. GE was not different between $\mathrm{T} 1$ and $\mathrm{T} 2$ $(17.0 \% \pm 0.9 \%$ vs. $17.0 \% \pm 0.9 \%, P=0.637)$ or between IG and CG $(17.2 \% \pm 0.9 \%$ vs. $16.7 \% \pm 1.0 \%, P=0.261)$.

\section{Maximal Time Trial}

Maximal TT performance was superior for IG compared to CG at both T1 and T2 $(P<0.05$, Table 3$)$. Mean speed and PO were increased from T1 to T2 $(P<0.05$, Fig. 3$)$, but no differences were found between $\mathrm{T} 1$ and $\mathrm{T} 2$ when analyzing
IG and CG separately. Absolute and relative $\mathrm{VO}_{2 \max }$ and $\mathrm{MR}_{\mathrm{ae}}$ increased from T1 to $\mathrm{T} 2(P<0.01)$, while $\mathrm{RER}_{\text {max }}$ and maximal BLa decreased $(P<0.05)$, without other differences in physiological variables (Table 3) or RPE. When separating the groups, both IG and CG increased their absolute and relative $\mathrm{VO}_{2 \max }$ and $\mathrm{MR}_{\mathrm{ae}}$, while IG decreased $\mathrm{RER}_{\max }$ and maximal BLa between $\mathrm{T} 1$ and $\mathrm{T} 2$. No difference in change scores (from T1 to T2) were found between groups for the maximal TT. The ANCOVA with TT speed at T1 as a covariate only showed a difference between $\mathrm{T} 1$ and $\mathrm{T} 2$ for maximal BLa (time $P=0.013$, $\eta_{\mathrm{p}}{ }^{2}=0.369$, interaction $\left.P=0.048, \eta_{\mathrm{p}}{ }^{2}=0.252\right)$ and between test occasions and groups for maximal RPE legs [T1: IG 18 (17-19), CG 20 (18-20); T2: IG 19 (18-20), CG 19 (18-20); time $P=0.013, \eta_{\mathrm{p}}{ }^{2}=0.363$, group $P=0.049$, $\eta_{\mathrm{p}}{ }^{2}=0.249$, interaction $\left.P=0.010, \eta_{\mathrm{p}}{ }^{2}=0.389\right]$.

Table 3 Mean \pm SD responses to skiing with the rifle during the two submaximal workloads and the maximal time trial (900 $\mathrm{m}$ for females, $1000 \mathrm{~m}$ for males) measured before (T1) and after (T2) the training intervention

\begin{tabular}{|c|c|c|c|c|c|c|c|}
\hline & \multicolumn{2}{|c|}{ Intervention group } & \multicolumn{2}{|c|}{ Control group } & \multicolumn{3}{|c|}{ Significant $p$ value $\left(\eta_{\mathrm{p}}^{2}\right)$} \\
\hline & $\mathrm{T} 1$ & $\mathrm{~T} 2$ & $\mathrm{~T} 1$ & $\mathrm{~T} 2$ & Group & Time & Interaction \\
\hline Submaximal workload 2 & $n=10$ & $n=10$ & $n=7$ & $n=7$ & & & \\
\hline $\mathrm{VO}_{2}(\mathrm{~L} / \mathrm{min})$ & $3.0 \pm 0.6$ & $2.9 \pm 0.6$ & $2.9 \pm 0.6$ & $2.9 \pm 0.5$ & NS (0.007) & NS $(0.021)$ & NS (0.017) \\
\hline $\mathrm{VO}_{2}(\mathrm{~mL} / \mathrm{kg} / \mathrm{min})$ & $41.5 \pm 5.4$ & $41.4 \pm 5.4$ & $41.5 \pm 5.8$ & $41.6 \pm 5.4$ & NS $(0.000)$ & NS (0.000) & NS (0.003) \\
\hline HR (beats/min) & $155 \pm 13$ & $153 \pm 11$ & $165 \pm 11$ & $164 \pm 12$ & NS (0.212) & NS $(0.033)$ & NS $(0.000)$ \\
\hline RER & $0.93 \pm 0.03$ & $0.91 \pm 0.03$ & $0.94 \pm 0.03$ & $0.93 \pm 0.04$ & NS (0.056) & NS (0.129) & NS (0.002) \\
\hline Blood lactate (mmol/L) & $2.2 \pm 0.7$ & $2.0 \pm 0.7$ & $2.4 \pm 0.8$ & $2.0 \pm 1.0$ & NS (0.005) & NS (0.208) & NS (0.047) \\
\hline Sub 4mmol & $n=10$ & $n=10$ & $n=7$ & $n=7$ & & & \\
\hline $\mathrm{VO}_{2}(\mathrm{~L} / \mathrm{min})$ & $3.5 \pm 0.5$ & $3.5 \pm 0.5$ & $3.3 \pm 0.6$ & $3.3 \pm 0.5$ & NS (0.037) & NS $(0.001)$ & NS (0.010) \\
\hline $\mathrm{VO}_{2}(\mathrm{~mL} / \mathrm{kg} / \mathrm{min})$ & $49.5 \pm 3.6$ & $49.6 \pm 4.4$ & $48.4 \pm 6.5$ & $48.5 \pm 5.4$ & NS (0.013) & NS (0.008) & NS $(0.000)$ \\
\hline HR (beats/min) & $172 \pm 11$ & $169 \pm 11$ & $180 \pm 8$ & $178 \pm 9$ & NS $(0.170)$ & NS $(0.200)$ & NS (0.001) \\
\hline RER & $0.97 \pm 0.03$ & $0.97 \pm 0.02$ & $1.00 \pm 0.03$ & $0.98 \pm 0.04$ & NS (0.185) & NS $(0.228)$ & NS (0.108) \\
\hline Blood lactate $(\mathrm{mmol} / \mathrm{L})$ & $3.5 \pm 0.7$ & $3.4 \pm 0.9$ & $4.1 \pm 0.9$ & $3.6 \pm 1.2$ & NS (0.069) & NS (0.117) & NS (0.040) \\
\hline Maximal time trial & $n=10$ & $n=10$ & $n=7$ & $n=7$ & & & \\
\hline Time (s) & $210.1 \pm 15.9$ & $205.3 \pm 18.2$ & $230.9 \pm 9.2^{\#}$ & $222.7 \pm 12.9^{\#}$ & $0.015(0.333)$ & $0.017(0.324)$ & $\mathrm{NS}(0.031)$ \\
\hline Mean speed $(\mathrm{m} / \mathrm{s})$ & $4.50 \pm 0.23$ & $4.61 \pm 0.26$ & $4.07 \pm 0.32^{\#}$ & $4.22 \pm 0.33^{\#}$ & $0.006(0.404)$ & $0.011(0.356)$ & NS (0.016) \\
\hline $\mathrm{VO}_{2 \max }(\mathrm{L} / \mathrm{min})$ & $4.3 \pm 0.8$ & $4.4 \pm 0.9^{*}$ & $3.9 \pm 0.8$ & $4.1 \pm 0.8 *$ & NS $(0.051)$ & $0.001(0.574)$ & NS (0.008) \\
\hline $\mathrm{VO}_{2 \max }(\mathrm{mL} / \mathrm{kg} / \mathrm{min})$ & $59.9 \pm 6.9$ & $62.5 \pm 8.6^{*}$ & $56.7 \pm 8.4$ & $59.4 \pm 8.8^{*}$ & NS (0.039) & $0.001(0.575)$ & NS $(0.001)$ \\
\hline $\mathrm{HR}_{\max }$ (beats/min) & $191 \pm 11$ & $191 \pm 10$ & $197 \pm 5$ & $194 \pm 6$ & NS (0.072) & NS (0.086) & NS (0.100) \\
\hline $\mathrm{RER}_{\max }$ & $1.23 \pm 0.02$ & $1.21 \pm 0.03^{*}$ & $1.19 \pm 0.05$ & $1.17 \pm 0.04$ & $0.012(0.350)$ & $0.009(0.371)$ & NS $(0.001)$ \\
\hline Maximal BLa (mmol/L) & $14.2 \pm 02.8$ & $12.7 \pm 1.8^{*}$ & $12.2 \pm 3.5$ & $10.6 \pm 1.9$ & NS (0.194) & $0.026(0.228)$ & NS (0.003) \\
\hline Mean PO (W) & $316 \pm 56$ & $321 \pm 58$ & $274 \pm 62$ & $284 \pm 62$ & NS (0.113) & $0.037(0.258)$ & NS (0.027) \\
\hline $\mathrm{MR}_{\mathrm{ae}}(\mathrm{W})$ & $1318 \pm 241$ & $1366 \pm 275^{*}$ & $1213 \pm 226$ & $1257 \pm 241^{*}$ & NS (0.049) & $0.002(0.478)$ & NS (0.002) \\
\hline $\mathrm{MR}_{\mathrm{an}}(\mathrm{W})$ & $514 \pm 112$ & $502 \pm 106$ & $427 \pm 113$ & $423 \pm 81$ & NS (0.154) & NS (0.033) & NS (0.009) \\
\hline$\sum \mathrm{O}_{2 \text { deficit }}(\mathrm{mL} / \mathrm{kg})$ & $72.4 \pm 12.5$ & $69.3 \pm 10.9$ & $68.1 \pm 14.5$ & $65.4 \pm 9.0$ & NS (0.034) & NS (0.155) & NS (0.001) \\
\hline
\end{tabular}

$V O_{2}$ oxygen uptake, $H R$ heart rate, $R E R$ respiratory exchange ratio, $B L a$ blood lactate, $P O$ power output, $M R_{a e}$ aerobic metabolic rate, $M R_{a n}$ anaerobic metabolic rate, $\Sigma O_{2 \text { deficit }}$ accumulated oxygen deficit, $N S$ not significant

*Significantly different from T1 (for the same group) based on Wilcoxon Signed Rank testing, $P<0.05$

${ }^{\text {\#} S i g n i f i c a n t l y ~ d i f f e r e n t ~ f r o m ~ I G ~(f o r ~ t h e ~ s a m e ~ t e s t ~ o c c a s i o n) ~ a c c o r d i n g ~ t o ~ M a n n-W h i t n e y ~} U$ testing, $P<0.05$ 
A

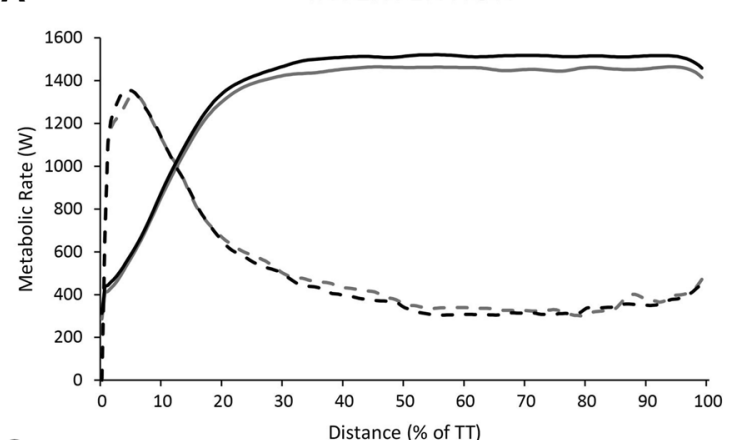

B

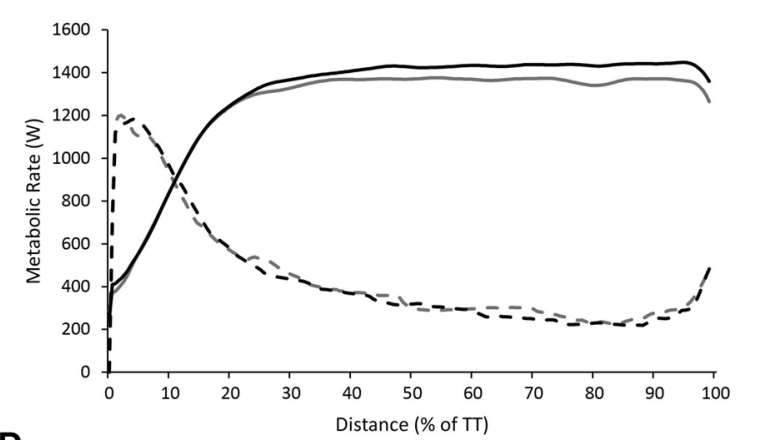

D

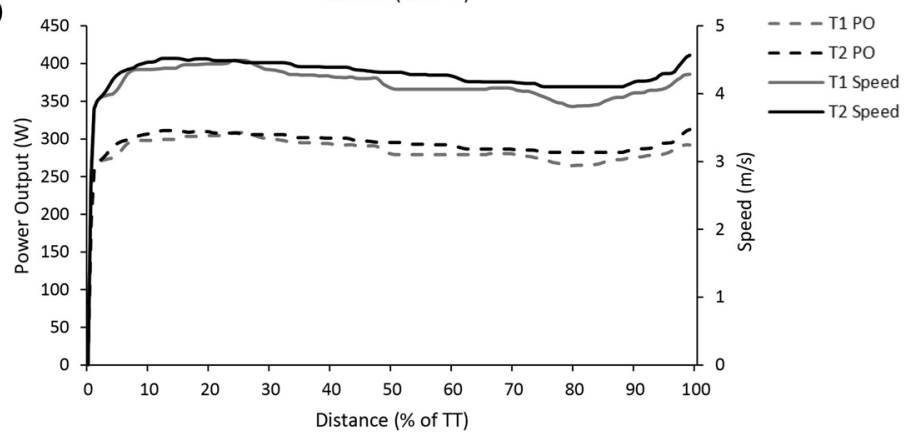

Fig. 3 Mean aerobic $\left(\mathrm{MR}_{\mathrm{ae}}\right)$ and anaerobic $\left(\mathrm{MR}_{\mathrm{an}}\right)$ metabolic rates $(\mathbf{a}, \mathbf{b})$ and speed and power output $(\mathbf{c}, \mathbf{d})$ during the maximal time trial for the intervention (IG) and control (CG) groups for testing before (T1) and after (T2) the training intervention

\section{Discussion}

The purpose of this study was to investigate whether an increased amount of training while carrying the rifle affects the physiology and performance of biathlon skiing in welltrained biathletes at submaximal and maximal workloads during a pre-season training period. During the training intervention, IG carried their rifle $\sim 2 \mathrm{~h}$ per week more compared to CG, but no differences in training effects between the groups during biathlon skiing were identified.

The goal for IG was to carry their rifle during at least two training sessions per week, but this target was not fully reached (mean \pm SD frequency was $1.5 \pm 0.6$ sessions per week for the group). If the participants had completed the targeted amount of rifle-carriage training it is possible that a difference between the groups would have been evident, although this remains speculative. Despite the shortcoming, IG still trained with the rifle for $\sim 2 \mathrm{~h}$ per week more than CG and around $20 \%$ of the total training time included rifle carriage for IG, while for CG this fraction was only $\sim 10 \%$. This is substantially lower than the proportions of $\sim 15 \%-30 \%$ reported previously $[9,15]$. However, the weekly training performed with the rifle was "estimated" by the athletes and/or coaches in the aforementioned studies, rather than being monitored and calculated exactly (as in the present study), which may partly explain this discrepancy. All training while carrying the rifle was performed as skate roller-skiing, and nearly $40 \%$ of the total training was performed using this exercise mode. To perform weightcarriage training during other training activities (e.g., running or cycling) may not be as effective for biathletes, since the movement patterns differ from skiing.

When skiing without the rifle, speed $_{@ 4 \text { mmol }}$ increased between $\mathrm{T} 1$ and $\mathrm{T} 2$ and when separated by the groups, this difference was significant for $\mathrm{CG}$ and there was a tendency for the same pattern in IG. Speed at the lactate threshold is an important factor for biathlon skiing performance [9, 23, 24], and Evertsen et al. [6] showed an increased running speed at the lactate threshold after 5 months of high-intensity training in elite XC skiers. The training period for the athletes in the present study was slightly shorter ( 16 weeks), but a comparable amount of high-intensity training was performed as in the study by Evertsen et al. [6]. Previous studies have shown that when skiing with the rifle BLa increases during higher workloads compared to skiing without the rifle, but not during lower (i.e., $<4$ mmol of BLa) workloads [9, 25, 26]. In the present study, $73 \%$ and $77 \%$ of the skate rollerskiing time at moderate and high intensities was performed with the rifle for IG, but no difference in BLa between T1 and $\mathrm{T} 2$ for the two submaximal workloads with the rifle was observed. This can be due to the low number of participants in the study, the relatively large variation in performance level (influenced by the inclusion of both females and males) and workloads that may have been too low to detect a difference (i.e., slightly below $4 \mathrm{mmol} / \mathrm{L}$ of BLa). Performance in the $\mathrm{TT}, \mathrm{VO}_{2 \max }$ and $\mathrm{MR}_{\mathrm{ae}}$ increased during the training 
intervention, while $\mathrm{MR}_{\mathrm{an}}$ and $\Sigma \mathrm{O}_{2 \text { deficit }}$ did not change. This is partly consistent with results presented by Losnegard et al. [17], whereby performance and $\Sigma \mathrm{O}_{2 \text { deficit }}$ increased between testing from June to October, while the $\mathrm{VO}_{2 \max }$ was unchanged. In the present study, there were no differences in change scores (i.e., between $\mathrm{T} 1$ and $\mathrm{T} 2$ ) between IG and $\mathrm{CG}$, indicating that the additional rifle carriage did not affect maximal biathlon skiing.

Several previous training studies lasting 8-22 weeks using military populations have shown an improvement in performance of up to $15 \%$ during a $3.2 \mathrm{~km}$ walking/running TT while carrying a load of $15-34 \mathrm{~kg}[7,8,12,29,30]$. A combination of strength and endurance training appears to have the largest effect on performance $[8,12,30]$, with the response amplified when including military load-carrying exercises as part of the training program [11]. This notion is supported by studies showing an increased performance in load-carriage exercise after just one additional load-carrying training session per week [7, 29, 30]. Explanations for not observing the same effects in the present study might be the difference in the mass of the load $(15-45 \mathrm{~kg}$ vs. $3.7 \mathrm{~kg})$, the difference in training status (inactive/moderately-active participants vs. well-trained athletes) and/or the difference in the training loads (3-10 h/week vs. 11-15 h/week). Thus, well-trained athletes that are accustomed to carrying a relatively light load might need a greater stimulus to increase load-carriage performance, which could be investigated in future studies.

The IG included members of the Swedish development team, who were interested in the effects of completing more training sessions with the rifle, while CG consisted of athletes matched as closely as possible according to performance level, and this group performed their normal training program. The CG only had seven participants due to difficulties in finding athletes at a performance level high enough to match the participants in IG. In addition, the standard deviation in both groups was relatively large, due to the inclusion of both males and females and within-group differences in performance levels. IG demonstrated superior TT performance at baseline compared to CG, but there were no differences between groups in physiological markers at the submaximal intensities with and without a rifle. The training volume was higher (by $\sim 4 \mathrm{~h} /$ week) for IG compared to CG during the intervention period and the fewer sick days in IG may have contributed to this difference [22]. The difference in baseline performance between the groups, the higher number of participants in IG, the high standard deviations in performance and the differences in training volume during the training period may have affected the results of the intervention. A more homogenous group of participants and a higher number of athletes in the IG may have shown differences between groups in physiological markers and/or biathlon skiing performance.
The submaximal testing without the rifle was part of the athletes' normal testing procedures, which are performed at least twice every year (May-June and September-October). To minimize additional visits to the laboratory, the normal testing protocols were used as part of the current study, in addition to the submaximal and maximal tests with the rifle. Due to different training programs and camps for the athletes, and in some cases sickness, the duration of the training intervention was not the same for all participants. However, additional ANCOVA analyses were performed using the duration of the training period, total training load and training intensity as covariates, showing no difference in the results. Two participants in the IG did not perform the testing without the rifle at $\mathrm{T} 2$, making the sample size slightly smaller for these follow-up tests. The small sample sizes are a limitation of the study, and in future studies, a higher number of participating athletes would be recommended. The maximal testing consisted of a TT lasting $900 \mathrm{~m}$ and $1000 \mathrm{~m}$ for women and men, respectively. Previous research has shown that a short-duration TT, compared to a traditional graded exercise protocol, is more reliable when measuring performance [20] and produces similar or even higher $\mathrm{VO}_{2 \max }$ values [16, 21]. For the maximal TT in the present study all tests except for two demonstrated at least three out of five criteria for $\mathrm{VO}_{2 \max }$ tests outlined by Cooke [4].

The limitations of the current study, such as the small sample size, different amounts of training completed by the two groups, differences in the intervention duration and variations in performance levels between the athletes, ought to be taken into consideration. However, these are common challenges for intervention studies involving highly-trained athletes with individual training programs, and when monitoring over a longer time period. More research in this area is therefore recommended to further increase the knowledge about the effects of rifle-carriage training on biathlon skiing performance.

\section{Conclusion}

According to the present results, increasing training while carrying the rifle by $2 \mathrm{~h}$ /week during 16 weeks does not appear to improve skiing performance in well-trained biathletes. In addition, physiological markers at submaximal and maximal intensities while carrying the rifle were not affected after the training intervention. Biathletes typically perform only a small amount of their endurance training with the rifle ( $\sim 10 \%-20 \%$ for the two groups in the present study) and this type of sport-specific training may need to be increased further in order to improve biathlon skiing performance.

Author Contributions MJK: initiated the study, collected and analyzed the data, and wrote the first draft of the manuscript; MSL: contributed 
to the study design and data analysis, and MSL and KM: contributed to the writing of the manuscript; MJK, KM and MSL: approved the final version to be published and agree to be accountable for all aspects of the work.

Funding Open Access funding provided by Mid Sweden University. This study was partly funded by the municipality of Östersund, Sweden.

\section{Compliance with Ethical Standards}

Conflict of interest The authors declare that they have no conflict of interest.

Ethics Approval All procedures followed were in accordance with the ethical standards of the responsible committee on human experimentation in Sweden and with the Declaration of Helsinki.

Consent to Participate Informed consent was obtained from all participants included in the study.

Open Access This article is licensed under a Creative Commons Attribution 4.0 International License, which permits use, sharing, adaptation, distribution and reproduction in any medium or format, as long as you give appropriate credit to the original author(s) and the source, provide a link to the Creative Commons licence, and indicate if changes were made. The images or other third party material in this article are included in the article's Creative Commons licence, unless indicated otherwise in a credit line to the material. If material is not included in the article's Creative Commons licence and your intended use is not permitted by statutory regulation or exceeds the permitted use, you will need to obtain permission directly from the copyright holder. To view a copy of this licence, visit http://creativecommons.org/licenses/by/4.0/.

\section{References}

1. Ainegren M, Carlsson P, Tinnsten M. Rolling resistance for treadmill roller skiing. Sports Eng. 2008;11:23-9. https://doi. org/10.1007/s12283-008-0004-1.

2. Andersson E, Holmberg HC, Ørtenblad N, Björklund G. Metabolic responses and pacing strategies during successive sprint skiing time trials. Med Sci Sports Exerc. 2016;48(12):2544-54. https://doi.org/10.1249/mss.0000000000001037.

3. Cohen J. Statistical power analysis for the behavioural sciences. Hillsdale: Lawrence Earlbaum Associates; 1988.

4. Cooke CB. Maximal oxygen uptake, economy and efficiency. In: Kinantropometry and exercise physiology laboratory manual: tests, procedures and data. 3rd ed. London: Routeledge; 2009. pp. 174-212.

5. Dzhilkibaeva N, Ahrens M, Laaksonen MS. Can performance in biathlon world cup be predicted by performance analysis of biathlon IBU cup? Int J Perform Anal Sport. 2019;19(5):85665. https://doi.org/10.1080/24748668.2019.1665884.

6. Evertsen F, Medbø JI, Bonen A. Effect of training intensity on muscle lactate transporters and lactate threshold of cross-country skiers. Acta Physiol Scand. 2001;173(2):195-205. https:// doi.org/10.1046/j.1365-201X.2001.00871.x.

7. Harman EA, Gutekunst DJ, Frykman PN, Nindl BC, Alemany JA, Mello RP, Sharp MA. Effects of two different 8-week training programs on military physical performance. J Strength Cond
Res. 2008;22(2):524-34. https://doi.org/10.1519/JSC.0b013 e31816347b6.

8. Hendrickson NR, Sharp MA, Alemany JA, Walker LA, Harman EA, Spiering BA, Hatfield DL, Yamamoto LM, Maresh CM, Kraemer WJ, Nindl BC. Combined resistance and endurance training improves physical capacity and performance on tactical occupational tasks. Eur J Appl Physiol. 2010;109(6):1197-208. https://doi.org/10.1007/s00421-010-1462-2.

9. Jonsson Kårström M, McGawley K, Laaksonen MS. Physiological responses to rifle carriage during roller-skiing in elite biathletes. Front Physiol. 2019;10:1-10. https://doi.org/10. 3389/fphys.2019.01519.

10. Joyner MJ, Coyle EF. Endurance exercise performance: the physiology of champions. J Physiol. 2008;586(1):35-44. https:// doi.org/10.1113/jphysiol.2007.143834.

11. Knapik JJ, Harman EA, Steelman RA, Graham BS. A systematic review of the effects of physical training on load carriage performance. J Strength Cond Res. 2012;26(2):585-97. https:// doi.org/10.1519/JSC.0b013e3182429853.

12. Kraemer WJ, Mazzetti SA, Nindl BC, Gotshalk LA, Volek JS, Bush JA, Marx JO, Dohi K, Gomez AL, Miles M, Fleck SJ. Effect of resistance training on women's strength/power and occupational performances. Med Sci Sports Exerc. 2001;33(6):1011-25. https://doi.org/10.1097/00005768-20010 6000-00022.

13. Laaksonen MS, Andersson E, Jonsson Kårström M, Lindblom $\mathrm{H}$, McGawley K. Laboratory-based factors predicting skiing performance in female and male biathletes. Front Sports Act Liv. 2020;2:1-8 https://doi.org/10.3389/fspor.2020.00099.

14. Laaksonen MS, Finkenzeller T, Holmberg HC, Sattlecker G. The influence of physiobiomechanical parameters, technical aspects of shooting, and psychophysiological factors on biathlon performance: a review. J Sport Health Sci. 2018;7(4):394-404. https://doi.org/10.1016/j.jshs.2018.09.003.

15. Laaksonen MS, Jonsson M, Holmberg HC. The Olympic biathlon-recent advances and perspectives after Pyeongchang. Front Physiol. 2018;9:1-6. https://doi.org/10.3389/fphys.2018. 00796.

16. Losnegard T, Myklebust H, Hallén J. Anaerobic capacity as a determinant of performance in sprint skiing. Med Sci Sports Exerc. 2012;44(4):673-81. https://doi.org/10.1249/MSS.0b013 e3182388684.

17. Losnegard T, Myklebust H, Spencer M, Hallén J. Seasonal variations in $V \mathrm{O}_{2 \max }, \mathrm{O}_{2}$-cost, $\mathrm{O}_{2}$-deficit, and performance in elite cross-country skiers. J Strength Cond Res. 2013;27(7):1780-90. https://doi.org/10.1519/JSC.0b013e31827368f6.

18. Luchsinger H, Kocbach J, Ettema G, Sandbakk O. The contribution from cross-country skiing and shooting variables on performance-level and sex differences in biathlon world cup individual races. Int J Sports Physiol Perform. 2019;14(2):1905. https://doi.org/10.1123/ijspp.2018-0134.

19. Luchsinger H, Kocbach J, Ettema G, Sandbakk Ø. Comparison of the effects of performance level and sex on sprint performance in the biathlon world cup. Int J Sports Physiol Perform. 2018;13(3):360-6. https://doi.org/10.1123/ijspp.2017-0112.

20. McGawley $\mathrm{K}$. The reliability and validity of a 4-min running time-trial in assessing $V \mathrm{O}_{2 \max }$ and performance. Front Physiol. 2017;8:1-9. https://doi.org/10.3389/fphys.2017.00270.

21. McGawley K, Holmberg HC. Aerobic and anaerobic contributions to energy production among junior male and female cross-country skiers during diagonal skiing. Int J Sports Physiol Perform. 2014;9(1):32-40. https://doi.org/10.1123/ijspp. 2013-0239.

22. Mårtensson S, Nordebo K, Malm C. High training volumes are associated with a low number of self-reported sick days in elite endurance athletes. J Sports Sci Med. 2014;13(4):929-33. 
23. Rundell KW. Treadmill roller ski test predicts biathlon roller ski race results of elite U.S. biathlon women. Med Sci Sports Exerc. 1995;27(12):1677-85.

24. Rundell KW, Bacharach DW. Physiological characteristics and performance of top U.S. biathletes. Med Sci Sports Exerc. 1995;27(9):1302-10.

25. Rundell KW, Szmedra L. Energy cost of rifle carriage in biathlon skiing. Med Sci Sports Exerc. 1998;30(4):570-6. https:// doi.org/10.1097/00005768-199804000-00015.

26. Stöggl TL, Bishop P, Höök M, Willis S, Holmberg HC. Effect of carrying a rifle on physiology and biomechanical responses in biathletes. Med Sci Sports Exerc. 2015;47(3):617-24. https:// doi.org/10.1249/mss.0000000000000438.

27. Swarén M, Supej M, Eriksson A, Holmberg HC. Treadmill simulation of Olympic cross-conutry ski tracks. In: Hakkarainen A,
Linnamo V, Lindinger SJ, editors. Science and nordic skiing II. Oxford: Meyer and Meyer Verlag; 2013. p. 237-42.

28. Weir JB. New methods for calculating metabolic rate with special reference to protein metabolism. J Physiol. 1949;109(12):1-9. https://doi.org/10.1113/jphysiol.1949.sp004363.

29. Williams AG, Rayson MP, Jones DA. Effects of basic training on material handling ability and physical fitness of British Army recruits. Ergonomics. 1999;42(8):1114-24. https://doi.org/10. 1080/001401399185171.

30. Williams AG, Rayson MP, Jones DA. Resistance training and the enhancement of the gains in material-handling ability and physical fitness of British Army recruits during basic training. Ergonomics. 2002;45(4):267-79. https://doi.org/10.1080/00140130210123525. 